\title{
Structural analysis of prosodic patterns: the case of excessive prolongations in Israeli Hebrew
}

\section{Vered SILber-VAROD}

Doctor in Linguistics. The Research Center for Innovation in Learning Technologies, The Open University of Israel, Israel.

veredsilber@gmail.com

Abstract:This paper proposes a new framework for prosodic pattern analysis, based on the study of excessive prolongation in spontaneous Israeli Hebrew. In order to reveal whether it is a random phenomenon or a predictable prosodic pattern, a multi-layer linguistic analysis was conducted. First, the phenomenon was taken out of its canonical research framework as a type of speech disfluency. Second, its acoustic characteristics were defined, and the phonological environments of these prolongations were accounted for. Finally, prolongations and their interface with the syntagmatic layer were analyzed. The proposed framework can serve as a format for other prosodic patterns as well.

Keywords: prosodic patterns; excessive prolongation; spontaneous Israeli Hebrew
Resumo: Este trabalho propõe um novo modelo para a análise do padrão prosódico, a partir do estudo do prolongamento excessivo na fala espontânea do hebraico israelense. Com 0 objetivo de verificar se se trata de um fenômeno aleatório ou um padrão prosódico previsível, procedeu-se a uma análise linguística multinível. Em primeiro lugar, o fenômeno não foi considerado um tipo de disfluência da fala, como é usualmente tratado. Em segundo lugar, as suas características acústicas foram descritas, e os seus ambientes fonológicos foram contabilizados. Finalmente, os prolongamentos e sua interface com a camada sintagmática foram analisados. 0 modelo proposto pode servir como um formato para outros padrões prosódicos.

Palavras chaves: prosodic patterns; excessive prolongation; spontaneous Israeli Hebrew 



\section{Introduction}

An effective approach to the study of prosody in spoken language seeks to identify prosodic patterns and their communicative values and to subsequently find a correlation between these patterns and other layers of linguistic structure.

This paper presents the prosodic pattern analysis of a specific pattern: the excessive prolongation in spontaneous Israeli Hebrew (IH). In order to determine whether it is a random phenomenon or a predictable prosodic pattern, a structural analysis was carried out. First, this phenomenon was taken out of its canonical research framework as a type of speech disfluency (hesitation). Second, its acoustic characteristics were defined, and the phonological environments of these prolongations were accounted for. The inclusion of a prosody-syntax interface in such a framework is also demonstrated.

Disfluency in natural spontaneous speech includes the pauses, prolongations, truncations, repetitions, selfrepairs, restarts, mispronunciations; "editing terms" such as oops, sorry, I mean; and hesitations such as err, eh, uh, $\mathrm{uhm}$. These phenomena present challenges for researchers in many different fields, ranging from speech production and perception in psychology, to conversational analysis and automatic speech recognition in speech technology. Disfluency types have been thoroughly investigated in several languages, including English, Swedish, Japanese, and French (for example, in English SHRIBERG (1994), CLARK AND WASSOW (1998), and SHRIBERG (2001). In Swedish, inter alia, EKLUND (2004), and ROLL, FRID AND HORNE (2007). In Japanese, WATANABE (2013)).

In fact, EKLUND (2004, p. 39) says that, in general, such disfluencies make up approximately $5 \%$ of spoken language. The present research, conducted on an 
IH spontaneous speech corpus, revealed the following disfluencies: 161 false starts (i.e., words that begin and are interrupted in the middle); 710 excessive prolongated word-final syllables; 355 hesitation markers pronounced as [e] 'eh'; 37 hesitation markers pronounced as [em] 'ehm'; 178 interjections pronounced as [a] 'uh'; and 491 discourse markers,(lexemes), consisting mostly of three words: /az/ 'so', /zot omeret/ 'I mean' and / keilu/ 'like'. To summarize, the disfluency rate is $6 \%$ of the 32,334 tokens corpus (not including 6,207 silent pauses $(>100 \mathrm{~ms})$ and 395 unintelligible words). This rate might be higher than the $5 \%$ reported above, due to the colloquial and spontaneous nature of the speech recordings (see The Corpus of Spoken Israeli Hebrew (CoSIH) for more details).

While SHRIBERG (2001) deals with hesitation disfluencies, she uses the term filled pauses (ibid, $\mathrm{p}$. 155). She also includes repetitions ('all the the tools), deletions or false starts ('it's-I could get it where I work), substitutions ('any health cover any health insurance), insertions ('and I felt I also felt'), and articulation errors ('and [pin] pistachio nuts').

Yet, from a prosodic standpoint, apart from filled pauses such as err, eh, uh, uhm, all other disfluencies consist of segmental increments, i.e. phenomena that represent a word, or part of a word/lexeme. Since the present research deals only with prosodic events, it will refer only to the 710 excessive prolongated word-final syllables mentioned above, and to the 355 hesitation markers pronounced as [e] 'eh'.

\section{Terminology conversion}

FLETCHER (2010) discusses two types of pauses: "pauses are often defined as either filled or unfilled/silent. ... filled pauses are disfluencies that consist generally of 
voiced material that can correspond to prolongated single vowels like 'uh' in English, or portions of syllables" (FLETCHER, 2010, p. 573).

In the present research, only perceptually silent pauses (over 100ms) are defined as pauses, and the prosodic events [e] 'eh' and [em] 'ehm', which are actually speech sounds, are annotated within the prosodic annotation scheme (see below). From the data in SILBER-VAROD (2013, p. 53-54), it is evident that (silent) pauses follow all types of prosodic boundaries, including minor ones (termed continuous boundaries). When pauses follow hesitations, it was found that approximately $27 \%$ of all hesitations in face-to-face dialogues are followed by a pause.

Another way of viewing [e]s and [em]s is by treating them as discourse markers, as in MASCHLER (2009, p. 23) who investigated discourse markers in a Hebrew database. The "filled pause terminology" is different from the "discourse marker terminology" in that the latter considers the [e] 'eh' as a lexical event, almost a lexical entry, which thus defines its gramaticization characteristics.

This fine distinction between:

A. types of disfluencies - segmental (deletions, insertions, repetition, false starts, etc.) versus suprasegmental (hesitation disfluency)

B. types of pauses - silent versus filled

C. types of discourse markers

precludes the use of the term 'hesitation disfluency' in this research.

Indeed, in the present research, the familiar terms 'filled pauses' and 'hesitation disfluencies' (CRUTTENDEN, 1997, p. 30; SHRIBERG, 2001; CARTER AND MCCARTHY, 2006, p. 172-173; FLETCHER, 2010, p. 573-575) are replaced with a prosodic perspective of 
this phenomenon. In SILBER-VAROD (2013) it was termed Continuous Elongated (CE) boundary tone.

Based on the new perspective suggested by the present research in the discussion below, the following issues should be explained:

1. Term conversion from filled pause or hesitation disfluency to continuous elongation

2. A shift from a disfluency phenomenon to a prosodic pattern

3. A wider account, which takes its syntactic environment, was carried in SILBER-VAROD (2013).

The first issue has been discussed in section 1 above. The following section will discuss the second issue regarding this prosodic pattern.

\section{A shift from disfluency to a prosodic pattern}

Regarding the shift from a disfluency phenomenon to a prosodic pattern, I would argue here that the same perceived disfluency phenomenon has several phonological manifestations but the same acoustic characteristics. The fact that two manifestations can be considered as a single phenomenon is a linguistic premise, and SHRIBERG (2001) refers to hesitations and filled pauses in this respect too:

"One of the most commonly observed effects of disfluency is a lengthening of rhymes or syllables preceding the interruption point. ... For example, in the utterance shown ..., there is a repetition disfluency of 'the the'. ... The first instance of 'the' (which constitutes the reparandum) is much longer than the second instance. ... This suggests that in the reparandum, speakers are signaling delay, hesitating much like they might display with a filled pause." (SHRIBERG, 2001, p. 161. My emphasis). 
Indeed, it seems reasonable to gather all types of realizations into one category - a prosodic pattern.

SILBER-VAROD (2010) showed that hesitation disfluencies in $\mathrm{IH}$ have three realizations, i.e. three distinct manifestations with regard to word-level phonology, all of which are perceived as excessive prolongation:

1. Prolongated syllables e.g., [ve:] 'and'.

2. Appended $e$ vowels that are inserted, as enclitics, after a word, but within the same intonation unit, e.g., /az/ 'so' which is pronounced [aze] 'so eh'.

3. Isolated [e] 'eh' or [em] 'ehm'.

The three realizations are demonstrated in Fig. 1-Fig. 3.

Figure 1 demonstrates excessive lengthening of wordfinal syllables. The first black frame shows the monosyllable subordinateparticle $[\mathrm{Se}]$ 'that, 'who', 'which' as being excessively prolongated (486ms long; the vowel part is $76 \%$ of it), and the second frame emphasizes the prolongated conjunction [ve] 'and' (422ms long; the vowel part is $93 \%$ of it).

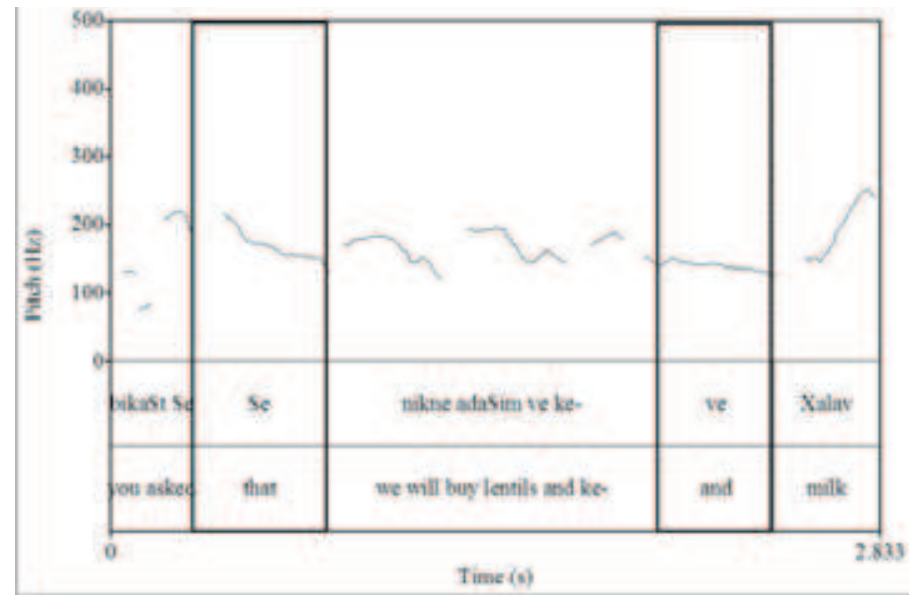

Fig. 1: An example of a syllable under excessive prolongation

The second realization occurs when an appended [e] is inserted after a word, as an enclitic, but within the same 
intonation unit. This research proposes the new notion that an (appended) [e] is (part of) a prolongated prosodic pattern. Fig. 2 demonstrates this attachment, which I consider to be a boundary marker. The last lexical word in the intonation unit is [Sel] 'of' with an appended [e] attached to it.

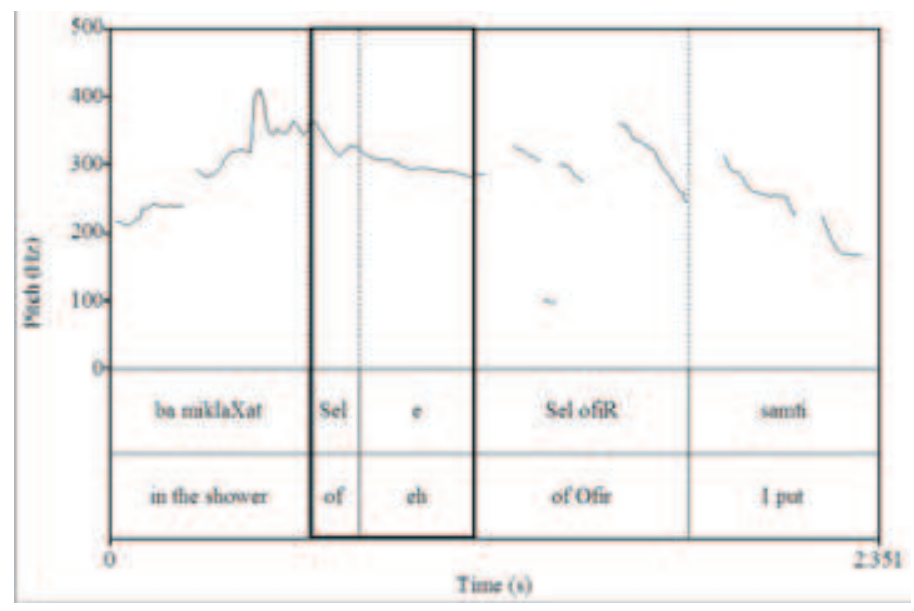

Fig. 2: An example of an appended [e] encliticized to a word

The third realization, demonstrated in Fig. 3, occurs when the speaker utters an isolated [e] 'eh' or [em] 'ehm'. This means that the intonation unit consists of only a single syllable, e.g. [e], which carries the prosodic pattern perceived as hesitation.

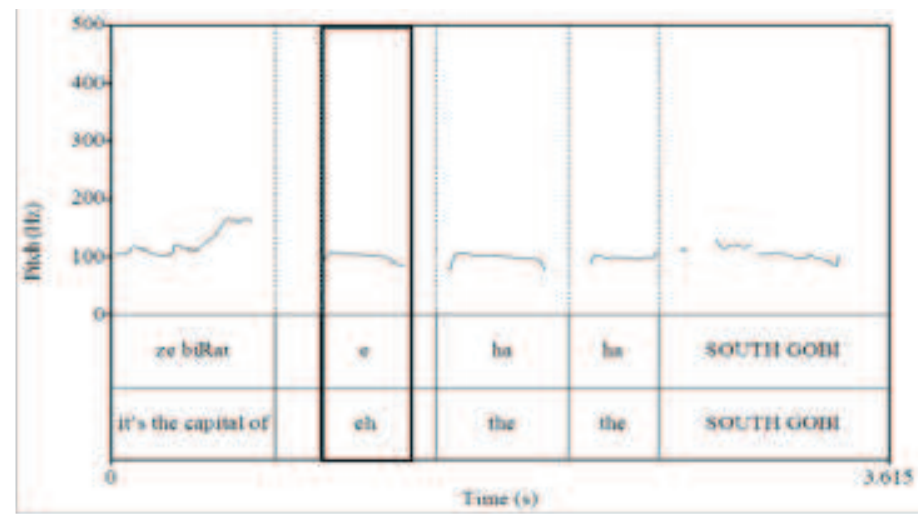

Fig. 3: An example of an isolated [e] between two silent pauses 
With these three manifestations in mind, a single term is necessary in order to refer to this prosodic phenomenon. In SILBER-VAROD $(2010 ; 2013)$ it was termed Continuous Elongation (CE), and it was defined as a prosodic boundary tone in $\mathrm{IH}$.

The phenomenon defined here as a CE boundary tone was previously mentioned in two other studies that explicitly referred to the issue of prosodic boundaries when discussing the hesitation phenomenon.

Within the framework of période intonative (LACHERET-DUJOUR AND VICTORRI, 2002), which consists of prosodic parameters only, the presence of hesitation disfluency blocks the possibility of a période boundary, and a minimal prosodic unit is marked by it - le groupe intonatif(intonation group). In other words, within the période intonative framework, the boundary after hesitation disfluencies is a minor one (annotated with a single slash [/] in (1)).

(1) tu prends le boulevard euh / là qui part de nef Chavant / là le boulevard qui passe à côté d'Habitat

The second reference to hesitations and prosodic boundaries is made by SHRIBERG (2001), who refers to the lengthening of disfluencies as different from the type of pre-boundary lengthening observed in fluent speech: "Durationally, the degree of lengthening can be far greater for disfluencies than for fluent boundaries, and the shapes of the distributions are different. The disfluency cases suggest a uniform probability of additional time in a hesitation, while fluent boundaries have a more symmetrical distribution. Second, they are different intonationally, since fluent pre-boundary lengthening is usually associated with a pitch movement conveying a boundary tone (e.g. continuation rise, final fall, etc.), whereas the lengthening accompanying disfluency tends 
to have a flat or slowly falling pitch contour much like those described ... for filled pauses. This is not surprising: lengthening, like uttering a filled pause, allows speakers to pause in the production of message content without ceasing phonation." (SHRIBERG, 2001, p. 161)

Both approaches view the CE boundary tone as a border, albeit a minor one, since both consider the phenomenon a "pause without a pause" mechanism. The present research does treat it as a continuous boundary tone, which among other continuous (C)-boundary patterns (SILBER-VAROD, 2013, p. 47-51) has a communicative value signaling that the speakers wish to continue.

Before analyzing the acoustic characteristics of the CE boundary tone, the database on which the research was performed will be introduced.

\section{Spontaneous Hebrew database}

The corpus used in this research contains 19 audio segments from 19 recordings that were selected from CoSIH. The recordings, which were made during 2001-2002, are of authentic IH everyday conversations. Each dialogue consists of conversations between one core speaker and various interlocutors with whom the speaker interacted on that day. The research corpus consists of 31,943 words (over 6 hours of speech) of which 4,419 are word-types (unintelligible speech events are not included). All recordings were manually transcribed according to the Speech Assessment Methods Phonetic Alphabet (SAMPA), which is the transcription method used in the present paper too.

\section{The phonetic realization of the CE boundary tone}

The phonetic characteristics of the CE boundary tone in $\mathrm{IH}$ will be described according to three acoustic parameters (cf. SILBER-VAROD, 2010): 
Formants (or vowel quality): CE boundaries in spoken Hebrew are mostly produced by the mid-front vowel [e]. Fig. 4 demonstrates this by a combined sound sample of artificially concatenated elongated syllables. Formant measurements correlate to the [e] vowel formants found in MOST, AMIR AND TOBIN (2000, p. 297-298).

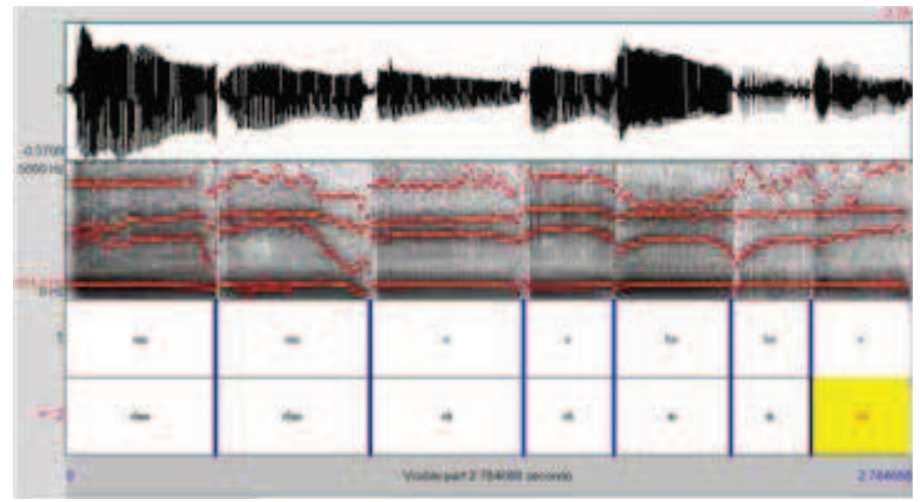

Fig. 4: Concatenated mid-front [e] vowels as realized carrying the $\mathrm{CE}$ boundary tone in spoken $\mathrm{IH}$

FOX (2000) suggests that the hesitation vowel used by speakers is different even in speakers of different varieties of English. This is also suggested by SHRIBERG (1994), who says that "Filled pauses have variants in many (perhaps all) languages, but their vowel quality varies predictably with the vowel inventory of the language" (ibid, p. 24-25). SHRIBERG (1994) demonstrates how disfluency is also associated with alternations in vowel quality - a prolongated the is pronounced as the variant [Di] (ibid, p. 163). CRUTTENDEN (1997) provides additional examples of the differences in the sound of filled pauses between dialects and languages: "In R.P. and in many other dialects of English the latter [the filled pause] typically involves the use of a central vowel [ə] ... in Scottish English a sound in the region of the vowel in gate and play is typical while in Russian an alveolar nasal is more common than a bilabial nasal" (CRUTTENDEN, 
1997, p. 30). In French, it is the closed-mid front vowel [ø], like euh, while in American English, it is the openmid back vowel $[\Lambda]$, like $u h$ or a vowel close to schwa, as mentioned in SHRIBERG (2001, p. 164).

$f_{\sigma}$ : A CE boundary is produced on a level-tone (Flat intonation in PORTES AND BERTRAND's (2006) labeling system). A level-tone is defined as the average key for the speaker. The measurements of the fundamental frequency of a single female speaker have shown that the tone of the prolongated vowel is $192 \mathrm{~Hz}$ on average (Fig. 5).

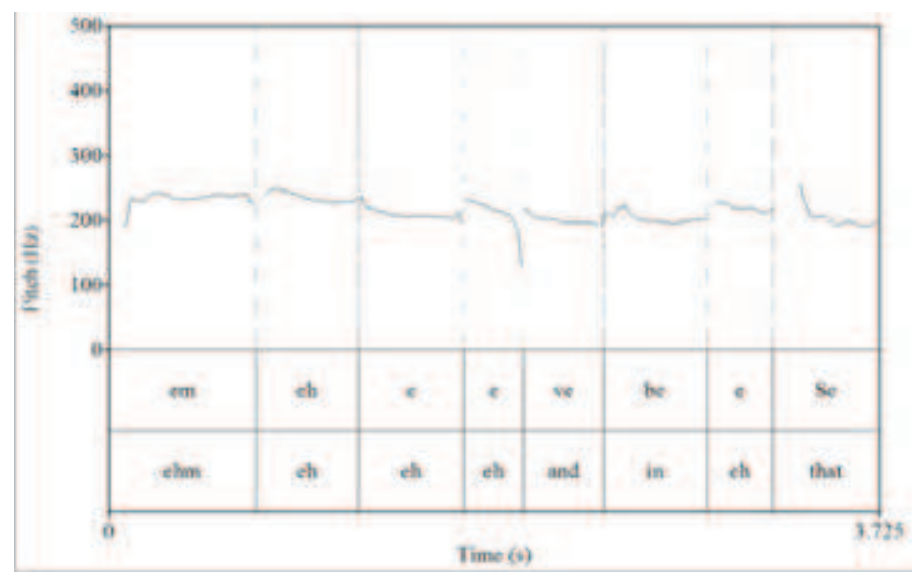

Fig. 5: A level tone of female speaker, as realized at CE boundaries of spoken $\mathrm{IH}$

SHRIBERG (1994) notes that filled pauses tend to be low in $f_{0}$ and to show a level or slightly falling $f_{0}$ pattern. More specifically, she found that clauseinternal filled pauses were uttered at an $f_{o}$ that could be predicted from the $f_{0}$ of the closest preceding peak $f_{0}$. SHRIBERG (1994) suggests that "filled pauses (at least those occurring within a clause) are intonationally wellformed" (SHRIBERG, 1994, p. 25).

Duration: Syllables carrying the CE boundary tone differ dramatically from other syllables in duration. In the present research, all syllables carrying CE tones 
were annotated as such only above a threshold of $230 \mathrm{~ms}$ in order to have a clear-cut definition of the CE boundary. The decision to set the threshold at 230ms was made after a pilot study carried out on two representative recordings, one from a face-to-face dialogue and the other from a telephone conversation (see SILBER-VAROD, 2013, p.70-73).

\section{Phonological environments of CE boundary tones}

All possible phonological environments of CE tones are mapped in Table 1, which presents a scheme of the possible syllabic structures that can be found in word-final syllables and the corresponding expected prolongation type - either syllable prolongation or an appended [e]. The first column specifies open vs. closed syllable structures. The next column shows the possible final segments in the syllable. It is demonstrated in that column that while in closed syllables any consonant can be prolongated in both techniques (prolongation or appended [e]), when it is an open syllable, only four ([i], [a], [o], [u]) out of the five vowels (including e) in IH can be prolongated with an appended [e]. An open syllable ending with $[\mathrm{e}]$ cannot be separated, by the listener, for its two /e/ sequences: the word-internal [e] and the appended [e].

The prolongated segment column details which segments are expected to undergo prolongation: the vowel in the case of an open syllable, such as in [o:] 'or', [keilu: ] 'as if', [be: ] 'in'; or an appended $e$ in the case of open syllables that do not end with an $e$, such as in [ha-e] 'the eh'. In the case of closed syllables, either the nucleus vowel or the final consonant, in the case of sonorant or continuant codas, may be lengthened. It is also possible for stops to be lengthened, as in the case of 
the Swedish disfluencies att 'that' and och 'and', which were documented and analyzed in ROLL, FRID AND HORNE (2007). Nevertheless, an appended [e] is generally expected following closed syllables, as in [aval-e] 'but eh'.

The Measure of duration column indicates which segments should be measured with respect to their duration in each syllabic structure. The Threshold column details the cases where a threshold of $230 \mathrm{~ms}$ is set. It should be noted that in many cases, perceived prolongation were ruled out because of this $230 \mathrm{~ms}$ threshold. In cases of appended [e]s, no duration measurements should be carried out and appended [e] cases are automatically marked as CE boundaries.

\begin{tabular}{|l|l|l|l|l|}
\hline $\begin{array}{l}\text { F i n a l } \\
\text { syllable } \\
\text { type }\end{array}$ & Final segment & $\begin{array}{l}\text { Prol on g a t e d } \\
\text { segment }\end{array}$ & $\begin{array}{l}\text { Measure of } \\
\text { duration }\end{array}$ & Threshold \\
\hline \multirow{2}{*}{ Open } & Any vowel & vowel & onset+nucleus & $>230 \mathrm{~ms}$ \\
\cline { 2 - 5 } & Only $a, i, o$, or $u$ & appended $[\mathrm{e}]$ & N/A & $\begin{array}{l}\text { Any length of } \\
\text { appended [e] }\end{array}$ \\
\hline \multirow{2}{*}{ Closed } & Any consonant & vowel+consonant & nucleus+coda & $>230 \mathrm{~ms}$ \\
\cline { 3 - 5 } & appended [e] & N/A & $\begin{array}{l}\text { Any length of } \\
\text { appended [e] }\end{array}$ \\
\hline
\end{tabular}

Table 1: Phonological scheme of CE boundaries in IH

Fig. 6 summarizes the syllable types in three prosodic variables. The left cone reflects the distribution of word-final syllables in fluent speech (non-prolongated syllables). In the IH corpus, the distribution of syllable types is $55 \%$ open and $43 \%$ closed ( $2 \%$ diphthongs, e.g., final [ey], [ay], [ow] segments). The center cone reflects the syllable type distribution in prolongated word-final syllables. Clearly, this distribution is biased towards open vowels (87\%), meaning that $\mathrm{IH}$ speakers prolongate mostly open word-final syllables. The right cone reflects this distribution in word-final syllables with an appended e. Clearly, the distribution again is different than in fluent speech. Most IH speakers (92\%) tend to append 
[e] immediately after closed syllables. The results are statistically significant (face-to-face sub-corpus: $\chi 2=430$; telephone conversations sub-corpus: $\chi 2=179$; $\mathrm{p}<0.001$ ).

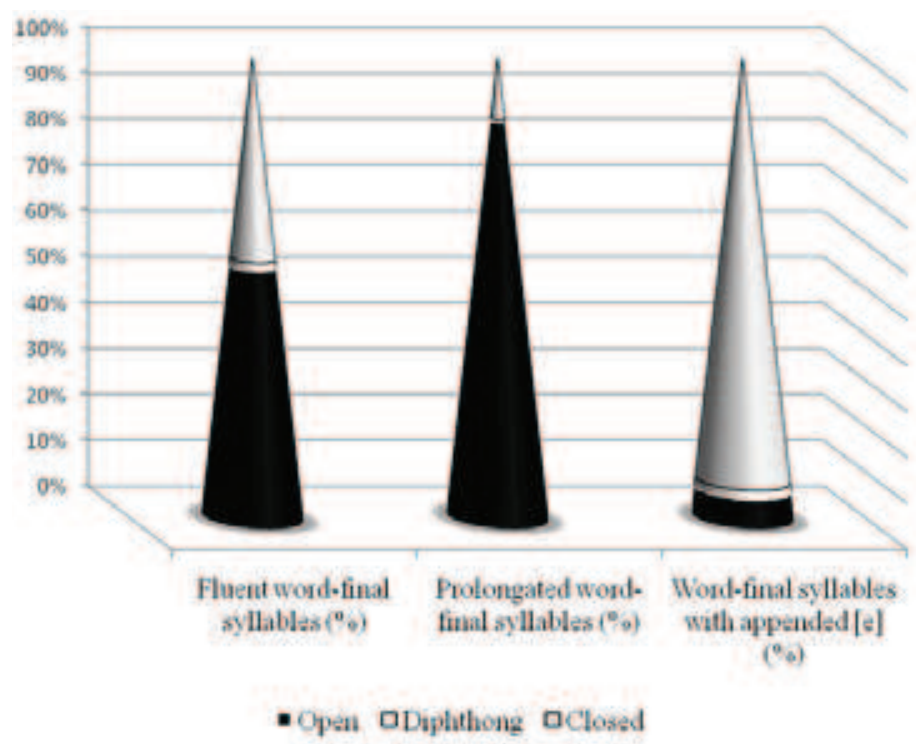

Fig. 6: Occurrences of word-final syllable types per prosodic variable in the corpus

The results can be interpreted as the mechanism with which IH speakers manipulate the prolongation. I would argue that this is the same phenomenon, but a different phonological manifestation. Still, it should be mentioned that the two manifestations also occur in other syllable types; i.e. closed syllables are also lengthened, and an appended $[\mathrm{e}]$ is also attached to open syllables. This was also found by ROLL, FRID, AND HORNE (2007, p. 229), who measured the durations of the monosyllabic word att 'that' in Swedish, both in fluent and disfluent environments.

\section{Syntactic aspects of prolongations}

The last observation that will be mentioned briefly here is the prosodic-syntactic interface of the excessive 
prolongation phenomenon. In SILBER-VAROD (2013), it was found that prolongations in IH do not occur randomly, but that they serve a specific cognitive function. This is reflected in the syntactic environment, where they most likely occur in IH as prolongated conjunctions (e.g., [ve] 'and'), possessive markers [Sel] 'of', definite articles [ha] 'the', and other function words such as prepositions. This can be explained by mapping the relationship between linguistic and cognitive complexity. It is suggested here, according to GIVÓN (2009), that the ease of production on the prosodic level is reflected by fluent speech, while more coding material is revealed by excessive prolongations. On the syntactic level however, the ease of production actually "reflects its degree of mental accessibility" (ARIEL, 2001). Function words are known as the most cognitively accessible, according to ARIEL (2001), while content words are the least accessible and consist more of coding material, as GIVÓN (2009) says: “... More complex mentally-represented events are coded by more complex linguistic/syntactic structures; ... More complex mentally-represented events require more complex mental processing operations. ... More complex syntactic structures require more complex mental processing operations." (ibid, 2009, p. 283). This analysis is represented by Fig. 7. The two dark gray boxes reflect the increments that occur together (excessive prolongations on function words), while the two white boxes usually follow excessive prolongations - a fluent production of content word (see SILBER-VAROD, 2013, p. 97).

\begin{tabular}{|l|l|l|}
\hline & Ease of production & More coding material \\
\hline Prosody & Fluent speech & Excessive prolongations \\
\hline Syntagma & Function words & Content words \\
\hline
\end{tabular}

Fig. 7: Prosody-syntax relations as reflected in the excessive prolongation 


\section{Discussion}

In the present research several linguistic levels were examined with regard to the single phenomenon of excessive prolongations. First it was analyzed perceptually, after which several acoustic measures were carried out in order to define its characteristics in IH. On the phonological level, the final-syllable structure was studied to determine its correlation to the manifestation of excessive prolongation. Results have shown that there is a significant correlation between the last syllable structure and the realization of prolongations. Yet, this systematic phonological behavior cannot be the explanation of the linguistic motivation of the prolonged words. For example, the word [rotse] (masculine singular verb form of 'wants') ends with a CV structure as well. Does this mean it will most probably be prolongated? Another word [mayim] 'water' ends with the nasal [m]. Does the fact that it is a nasal continuant predict its prolongation over other words?

With the structural multi-level analysis described here, it seems that the phenomenon of excessive prolongations - termed here the CE boundary tone - does not depend on the phonological structure of words, since it has been shown that the final-syllable structure does not prevent IH speakers from prolonging syllables, which they also do with an appended [e]. Once this regularity was found, the linguistic motivation for excessive prolongations was discussed on the syntagmatic level. It has been shown that, as in other languages, this phenomenon mostly occurs on function words.

\section{Summary and future research}

In the present research, three types of prolongations have been assembled into a single prosodic pattern termed the CE boundary tone. Such an 
approach allows for comparative cross-linguistic studies that examine this perceptual interpretation (e.g. that the speaker wants to continue), universal features (e.g. prolongation), as well as language-dependent features (e.g. the elongated vowel quality).

Results and analysis of the findings suggest that excessive prolongations in IH form a pattern which requires parallel segmental and suprasegmental mechanisms. The CE tone, which is mostly perceived as hesitation, is one of the techniques that the speaker uses to signal that he or she has more to say. This prosodic manifestation is executed when phonological structures on the segmental level easily allow it (in open syllables at morpheme final position) or when phonology seemingly blocks it and thus the prosodic structure "finds its way out" (with an appended [e] vowel). This prosodic pattern is thus a bridge over two intonation units that are syntactically dependent. This mechanism maintains the flow of speech, or the speech chaining.

The structural analysis suggested here can serve as a format for the analysis of other prosodic patterns as well. Like the $\mathrm{CE}$ boundary tone, any prosodic pattern can be analyzed for its communicative value, phonetic realization, phonological structure, and syntagmatic environment.

Although a comprehensive analysis was presented above, excessive prolongations in IH still need to be thoroughly investigated on several levels. First, acoustic measurements should be conducted on the entire corpus. Moreover, although results on the syntagmatic level are well studied, the syntactic level analysis should be widened and a segmentation of deep syntactic structures of the corpus should be conducted in order to compare results in other languages and in order to predict excessive prolongations with regard to syntactic complexity. 


\section{References}

ARIEL, M. Accessibility theory: An overview. In: SANDERS, T.; SCHLIPEROORD, J.; SPOOREN, W., Text representation: Linguistic and psycholinguistic aspects. Amsterdam: John Benjamins, 2001, p. 29-87.

CLARK, H. H.; WASOW, T. Repeating words in spontaneous speech. Cognitive Psychology, v. 37, i. 3, p. 201-242, 1998.

CRUTTENDEN, A. Intonation. Cambridge: Cambridge University Press, 1997.

CARTER, R.; MCCARTHY, M. Cambridge grammar of English: A comprehensive guide: Spoken and written English grammar and usage. Cambridge: Cambridge University Press, 2006.

COSIH, The corpus of spoken Israeli Hebrew. Available at: <http://humanities.tau.ac.il/ ${ }^{\sim}$ cosih/english/index.html $>$. Accessed in: 31 August, 2013.

EKLUND, R. Disfluency in Swedish human-human and human-machine travel booking dialogues. Department of Computer and Information Science, Linköping Studies in Science and Technology Dissertation, n. 882, 2004.

FLETCHER, J. The prosody of speech: Timing and rhythm. In: HARDCASTLE, W. J.; LAVER, J.; GIBBON, F. E. The handbook of phonetic sciences, 2nd ed. West Sussex: WileyBlackwell, 2010, p. 523-602.

FOX, A. Prosodic features and prosodic structure: The phonology of suprasegmentals. New York: Oxford University Press, 2000.

GIVÓN, T. The Genesis of Syntactic Complexity: Diachrony, Ontogeny, Neuro-cognition. Amsterdam: John Benjamins Publishing, 2009. 
LACHERET-DUJOUR, A.; VICTORRI, B. La période intonative comme unité d'analyse pour l'étude du français parlé: Modélisation prosodique et enjeux linguistiques. In: CHAROLLES, M. Verbum 1, n. 24, 2002, p. 55-72.

MASCHLER, Y. Metalanguage in interaction: Hebrew discourse markers. Amsterdam: John Benjamins, 2009.

MOST, T.; AMIR, O.; TOBIN, Y. The Hebrew vowel system: Raw and normalized acoustic data. Language and Speech, v. 43, n. 3, p. 295-308, 2000.

PORTES, C.; BERTRAND, R. Some cues about the interactional value of the 'continuation' contour in French. Paper read at the International Symposium of DiscourseProsody as a complex interface (IDP05), 2006. Available at: $<$ http://aune.lpl.univ-aix.fr/ prodige/idp05/actes/portes_ bertrand.pdf $>$. Accessed in: 31 August, 2013.

ROLL, M.; FRID, J.; HORNE, M. Measuring syntactic complexity in spontaneous spoken Swedish. Language and Speech, v. 50, n. 2, p. 227-245, 2007.

SAMPA (Speech Assessment Methods Phonetic Alphabet). SAMPA for Hebrew. Available at: http://www.phon.ucl.ac.uk/ home/sampa/hebrew.htm. Accessed in: 31 August. 2013.

SHRIBERG, E. Preliminaries to a theory of speech disfluencies. Doctoral dissertation, Department of Psychology, University of California, Berkeley,1994.

To 'errrr' is human: Ecology and acoustics of speech disfluencies. Journal of the International Phonetic Association. v. 31, n. 1, p. 154-169, 2001.

SILBER-VAROD, Vered. The SpeeCHain Perspective: Form and Function of Prosodic Boundary Tones in Spontaneous Spoken Hebrew. LAMBERT Academic Publishing, 2013. 
Phonological aspects of hesitation disfluencies.

Proceedings of Speech Prosody 2010, Chicago, USA, May 14-19, 2010. Available at: <http://www.speechprosody2010.

illinois.edu/papers/100020.pdf >, Accessed in: 31 August, 2013.

WATANABE M. Phrasal complexity and the occurrence of filled pauses in presentation speeches in Japanese. In: EKLUND, R. (Ed.) Proceedings of DiSS 2013 - the $6^{\text {th }}$ workshop on disfluencies in spontaneous speech. Stockholm, Sweden, August 21-23, 2013, p. 71-72.

[Recebido em 31 de agosto de 2013 e aceito para publicação em 14 de novembro de 2013] 